\title{
Neuropsychological profile of patients with acute lymphoblastic leukemia
}

\author{
Ediana Rosselly de Oliveira-Gomes, Débora Sunaly Leite, Danielle Ferreira Garcia, Samantha \\ Maranhão, Izabel Hazin \\ Universidade Federal do Rio Grande do Norte, Natal, RN, Brazil
}

\begin{abstract}
The present study investigated cognitive function in children diagnosed with acute lymphoblastic leukemia (ALL). The subjects were 20 children between the ages of 6 and 12 years of both genders who were diagnosed with ALL and underwent exclusively triple intrathecal prophylactic chemotherapy of the central nervous system. The protocol used for the neuropsychological assessment included the following cognitive aspects: intellectual performance, attention, memory and executive function. Data were analyzed by descriptive and inferential statistics using the Mann-Whitney U test and Student $t$-test. The effects of gender, age at diagnosis, and time since the initiation of treatment on the children's performance were determined. The evaluation of intellectual performance revealed reduced scores in the group of children who were female and younger than 5 years of age at diagnosis, especially difficulty with verbal skills and working memory. With regard to attention systems, the different groups presented expected performance for their age. We observed lower scores in the different groups in executive function, aspects of the development of problem-solving strategies, self-regulation, cognitive flexibility and inhibitory control. Better performance was observed for episodic memory and semantic memory (immediate and recognition), but lower scores were found for learning and recall after interference. In conclusion, the present findings are both consistent and discordant with the literature in the field that alludes to the impact of chemotherapy on the maturation of the central nervous system.

Keywords: acute lymphoblastic leukemia; cognitive function; neuropsychological assessment; neurodevelopment; intrathecal chemotherapy.
\end{abstract}

Received 03 December 2012; received in revised form 17 December 2012; accepted 18 December 2012. Available online 28 December 2012.

\section{Introduction}

Data from the Brazilian Instituto Nacional do Câncer (2012) estimated that the incidence of pediatric tumors worldwide varies from $1 \%$ to $3 \%$ for all cases of cancer. Following this trend, the average incidence of pediatric tumors in the Brazilian Cancer Registries of the Population Base is $\sim 3 \%$. In Brazil, the annual incidence of new cases of cancer is estimated to be 384.340 . Therefore, $\sim 11,530$ new cases of cancer occur annually in children and adolescents up to 19 years of age.

Childhood leukemia comprises $30 \%$ of cancers. Among these, $75 \%$ of the cases correspond to acute lymphoblastic leukemia (ALL), 20-25\% correspond to acute myeloid leukemia and the remaining $1-3 \%$ of the cases correspond to chronic myeloid leukemia. Childhood leukemia results from a combination of

Ediana Rosselly de Oliveira Gomes, Débora Sunaly Leite, Danielle Ferreira Garcia, Samantha Maranhão, and Izabel Hazin, Programa de Pós-graduação em Psicologia da Universidade Federal do Rio Grande do Norte. Correspondence regarding this article should be directed to: Ediana Rosselly de Oliveira Gomes, UFRN/Centro de Ciências Humanas, Departamento de Psicologia, Campus Universitário, s/n Lagoa Nova. CEP: 59072-970 - Natal-RN - Brasil. E-mail: ediana.ogomes@gmail.com. genetic vulnerability and environmental factors. A variable sequence of mutagenic events that occur at different intervals may eventually trigger the disease. For leukemia in children $<12$ months of age, genetic aggravation and consequent mutations occur mainly during intrauterine life. For older children, a first mutagenic event is believed to occur during intrauterine life and a subsequent second event triggers the disease (Filho, Cristofani, Almeida \& Teixeira, 2012).

Although ALL is still the primary cause of death in children aged 0 to 5 years, since the last decade this disease has become more understood and curable as a result of the expansion of knowledge about the disease, more precise and earlier diagnosis, better delineation of prognostic factors and advances in pharmacology that led to the better integration of new drugs in specific therapeutic protocols (Pedrosa \& Lins, 2002; Leite et al., 2007).

However, because of the requirement to use high amounts of combined drugs during the many phases of treatment, evaluating potential direct drugs interactions and possible synergistic and antagonistic effects is important (Cazé, Bueno, \& Santos, 2010). An increasing number of children survive ALL, but further investigations of the secondary effects of the 
disease and its treatment are needed, notably those related to prophylactic treatment of the central nervous system (CNS) also known as preventive or prophylactic therapy, which is responsible for the increased cure rates in children (Temning \& Jenney, 2010).

Cranial radiotherapy is considered the most effective prophylactic treatment for ALL. However, because use of this technique may be associated with neurotoxicity and occasionally the occurrence of brain tumors, especially in children $<3$ years of age, this modality has been gradually replaced by additional doses of intrathecal chemotherapy (i.e., the drugs are directly injected into cerebrospinal fluid) and more intensive systemic chemotherapy (Pedrosa \& Lins, 2002). Although the latter has been considered the most suitable treatment approach, it has been associated with the appearance of mild cognitive deficits associated with arithmetic performance, attention, information processing, visual-motor integration and memory (especially verbal memory).The risk factors for these effects include an age of diagnosis of $<5$ years, female gender and treatment intensity (Temning \& Jenney, 2010).

According to Campbell et al. (2007), deficits in cognitive function are increasingly recognized as a consequence of the long-term treatment of ALL. However, studies have been inconsistent with regard to the affected domains and their degree of impairment, especially those that result from intrathecal chemotherapy used to prevent infiltration of neoplastic cells into the CNS. Additionally, few studies have used controlled experimental designs, reflected by the variability of the tests used and the limited availability of tools that evaluate children and the multifactorial aspects of the pathology and modern treatment protocols (Waber et al., 2007).

A review by Butler \& Haser (2006) found that the initial studies with children strongly focused on the effects of ALL and its treatment on intellectual performance and academic performance, whereas specific skills related to cognitive function were rarely studied. Cole \& Kamen (2006) suggested that cognitive alterations can be transitory or persistent, and despite the importance of neuroimaging, correlating the data derived from these techniques with neuropsychological assessment is not always possible. The impairments reported in the literature include declines in intellectual performance, academic performance, learning, memory, attention, concentration, speed of information processing, visual-spatial skills, psychomotor function and executive function (Neglia, O'Leary, \& Bathia, 2011; Waber et al., 2012).

The present study investigated the impact of intrathecal chemotherapy used for the treatment of ALL on attention, executive functions, memory systems and intellectual performance in children. We evaluated the variables suggested in the literature as those that most interfere with neuropsychological prognosis, including gender, age at time of diagnosis $(<5$ years old $v s$. $\geq 5$ years old), and treatment schedule - currently in treatment or off treatment (Gomes, 2011).

\section{Methods}

The present study was approved by the local ethics committee (Comitê de Ética em Pesquisa da Liga NorteRiograndense Contra o Câncer). Upon approval, an exploratory phase was initiated in which collaborations were established with medical and social assistance institutions for patients with ALL in Natal-RN, Brazil. These institutions included Liga Norte Riograndense Contra o Câncer, Hospital Infantil Varela Santiago, Casa de Apoio à Criança com Câncer Durval Paiva and Grupo de Apoio à Criança com Câncer.

\section{Sample}

Twenty children of both genders, aged 6 to 12 years, who were diagnosed with ALL participated in the study. Among these subjects, 10 were currently receiving treatment and 10 had not received treatment for at least 1 year. Fourteen of the subjects were girls and six were boys. Nine patients began treatment prior to the age of 5 years and 11 children were 5 years old or older at the time of diagnosis and the initiation of treatment. This age group was selected based on the age at which children are typically diagnosed with ALL, time of treatment and appropriateness of the evaluation tools. The subjects were only subjected to intrathecal chemotherapy as a treatment for the prevention of CNS diseases, given that the use of cranial radiotherapy is rare in the previously mentioned institutions.

Additionally, 76 healthy children from public and private schools and philanthropic institutions in Metropolitan Area of Natal participated in the study as control subjects to establish reference data for the following instruments: Story Recall (SR) and Rey's AuditoryVerbal Learning Test (RAVLT). This phase of the study was necessary because, although these tools are widely used, few studies have standardized these tools for the neuropsychological assessment of children and adolescents, which makes data interpretation difficult. In the present study, we selected at least five children of similar age and socioeconomic level for each child diagnosed with ALL. The average performance for each age group (from 6 to 12 years of age) was calculated. Finally, we used Z-scores to analyze the performance of each child with ALL.

\section{Instruments}

Table 1 presents the neuropsychological assessment protocol used and the functions evaluated in this study.

\section{Statistical Analyzes}

Data were processed to verify any contrasts that arose from the proposed methodology. Accordingly, unidimensional descriptive analyses of group means and standard deviations were used for the following evaluation tools. Inferential analyses were used to test significant differences between groups of subjects selected by the previous phase of the analysis. Score differences between groups as a function of the afore 
Table 1. Neuropsychological assessment protocol

\begin{tabular}{ll}
\hline Cognitive function & Instruments \\
\hline $\begin{array}{l}\text { Intellectual } \\
\text { performance }\end{array}$ & $\begin{array}{l}\text { Wechsler Intelligence Scale for Children } \\
\text { (WISC-III) } \\
\text { Raven's Colored Progressive Matrices } \\
\text { Test. }\end{array}$ \\
Attention systems & $\begin{array}{l}\text { Attention Cancellation Task (Montiel \& } \\
\text { Capovilla, 2007) }\end{array}$ \\
Executive function & $\begin{array}{l}\text { Wisconsin Card Sorting Test (WCST). } \\
\text { Memory }\end{array}$ \\
& $\begin{array}{l}\text { Rey's Auditory-Verbal Learning Test } \\
\text { (RAVLT); }\end{array}$ \\
& Logical Story-Story Recall Test \\
\hline
\end{tabular}

mentioned variables were analyzed using MannWhitney U or Student $t$-test, which was used only when the data were normally distributed (determined by Levene's test, with $p>.05$ as the criterion). Interpretative conclusions were constructed, in which the data from the quantitative analyses were combined with the data from the qualitative analyses.

\section{Results}

\section{Demographic characteristics of the groups}

Based on the initial interviews with the parents, all of the children were regularly attending school and exhibited adequate academic performance for their age, with the exception of two 6-year-old children who had not yet started school because they were currently undergoing treatment. All children were patients at Sistema Único de Saúde-SUS. Eight children were residents in the capital, and 12 children were residents in the interior of Rio Grande do Norte state. Children attended public or private schools or small philanthropic schools in their cities and belonged to medium or low economic classes.

Neuropsychological effects as a function of age at the time of diagnosis were separately analyzed by group (i.e., children who were currently undergoing treatment and children who were off treatment). This approach was used because of variability between the variables in terms of sample size, with more children who were diagnosed at the age of 5 years or older belonging to the first group. Four groups were then formed: (1) children who were $<5$ years old at the time of diagnosis and in treatment, (2) children who were 5 years old or older at the time of diagnosis and in treatment, (3) children who were $<5$ years old at the time of diagnosis and off treatment and (4) children who were 5 years old or older at the time of diagnosis and off treatment. Table 2 summarizes the frequency distribution of the subjects.

\section{Intellectual Performance}

Comparison between groups who were in treatment and off treatment indicated a slight difference in performance on both evaluation tools. This difference was characterized by better performance in children in treatment in all of the measures. Additionally, we found that the lowest scores in both groups were shown on the Freedom from Distractibility Index (FDI) of the WISC-III.

By comparing males and females, we observed better performance in males in all of the Intelligence Quotients (IQs) and factorial indices of the WISC-III, with a minimal

Table 2. Frequency distribution of subjects

\begin{tabular}{|c|c|c|c|c|c|}
\hline & & $\begin{array}{l}\text { In treatment } \\
(n=10)\end{array}$ & $\begin{array}{l}\text { Off treatment } \\
(n=10)\end{array}$ & $\begin{array}{l}<5 \text { years of age at } \\
\text { diagnosis } \\
(n=9)\end{array}$ & $\begin{array}{l}>5 \text { years of age at } \\
\text { diagnosis } \\
(n=11)\end{array}$ \\
\hline \multirow[t]{2}{*}{ Sex } & Male & 3 & 3 & 3 & 3 \\
\hline & Female & 7 & 7 & 6 & 8 \\
\hline \multirow[t]{8}{*}{ Age } & 6 & 2 & 0 & 1 & 1 \\
\hline & 7 & 4 & 3 & 4 & 3 \\
\hline & 8 & 2 & 1 & 2 & 1 \\
\hline & 9 & 0 & 2 & 1 & 1 \\
\hline & 10 & 1 & 1 & 1 & 1 \\
\hline & 11 & 2 & 0 & 0 & 2 \\
\hline & 12 & 2 & 0 & 0 & 2 \\
\hline & Mean (SD) & $8.0(2.2)$ & $8.9(1.6)$ & $7.7(1.2)$ & $9.1(2.2)$ \\
\hline \multirow[t]{9}{*}{ Education } & Alphabetization & & & & \\
\hline & $1^{\text {st }}$ year & 1 & 0 & 1 & 0 \\
\hline & $2^{\text {nd }}$ year & 2 & 1 & 2 & 1 \\
\hline & $3^{\text {rd }}$ year & 4 & 3 & 3 & 4 \\
\hline & $4^{\text {th }}$ year & 0 & 2 & 2 & 0 \\
\hline & $5^{\text {th }}$ year & 0 & 2 & 1 & 1 \\
\hline & $6^{\text {th }}$ year & 0 & 1 & 0 & 1 \\
\hline & Not in school & 2 & 1 & 0 & 3 \\
\hline & & 1 & 0 & 0 & 1 \\
\hline \multirow[t]{3}{*}{ School type } & Public & 5 & 10 & 6 & 9 \\
\hline & Private & 4 & 0 & 2 & 2 \\
\hline & $\mathrm{N} / \mathrm{A}$ & 1 & 0 & 1 & 0 \\
\hline Total & & $(n=20)$ & & $(n=20)$ & \\
\hline
\end{tabular}


difference of 8 points on the FDI and maximal difference of 17 points on the Verbal Comprehension Index (VCI). Statistical analysis revealed significant effects of gender and age at the time of diagnosis. Student $t$-test revealed a significant difference in performance between males and females on the Verbal Intelligence Quotient (VIQ) $(p=.031)$, Performance Intelligence Quotient (PIQ) $(p$ $=.037)$ and Full Scale Intelligence Quotient (FSQT) $(p$ $=.012$ ), with better performance in males. However, an opposite result was found on Raven's Colored Progressive Matrices (RPCM) (Table 6).

The analysis of performance as a function of the children's age at the time of diagnosis revealed better performance in the group in treatment who were diagnosed before 5 years of age. However, in the group off treatment, the results were opposite. The group of children who were $<5$ years old at the time of diagnosis had poorer performance (Table 3 ).

Student $t$-test revealed that the group of children who were $<5$ years old at diagnosis had better performance on the VIQ $(p=.029)$, PIQ $(p=.05), \operatorname{FSQT}(p=.011)$, VCI $(p=.033)$ and FDI $(p=.015)$ in the treatment group. Student $t$-test revealed effects of age at diagnosis on the PIQ $(p=.015)$ and Perceptual Organization Index (POI) $(p=.025)$, with poorer performance in children who were diagnosed before 5 years of age in the offtreatment group (Table 6).

\section{Attention systems}

Overall, global group and subgroup performance was not significantly different from the expected results for the corresponding age groups. Comparisons of performance as a function of in treatment, off treatment, gender and age at diagnosis did not reveal significant differences between groups or subgroups.

\section{Executive function}

Comparison of performance in the groups in treatment and off treatment on the WCST indicated that both groups had poorer performance than expected performance in Percent Perseverative Responses (PPR), Percent Perseverative Errors (PPE) and Learning to Learn (LL). Gender analysis also indicated poorer performance on these items.

With regard to age at the time of diagnosis in the group in treatment, we found overall better performance in the group diagnosed before 5 years of age. In the group off treatment, we found better performance in the group diagnosed at 5 years of age or older in the majority of the tests (Table 4). Statistical comparisons of groups and subgroups revealed a significant difference in performance only on LL in the group off treatment when considering the age at diagnosis, with poorer performance in the group diagnosed before 5 years of age $(p=.022)$ (Table 6).

\section{Memory}

Data demonstrated that the group off treatment had better results than the group in treatment. No gender difference was found for these measures.

With regard to age at diagnosis, we found better results in the treatment group in children diagnosed before 5 years of age. In the group off treatment, we found better results in children diagnosed before 5 years of age in the group in treatment.

Table 3. Mean and standard deviation of performance scores on the WISC-III and Raven's Colored Progressive Matrices (RCPM) as a function of group and subgroup

\begin{tabular}{llllllllll}
\hline Group & & VIQ1 & PIQ & FSIQ & VCI & POI & FDI & PSI & RPCM \\
\hline IT & Mean & 89.8 & 95.3 & 92.0 & 92.1 & 95.5 & 83.7 & 91.3 & 64 \\
& $(\mathrm{SD})$ & $(14.6)$ & $(11.4)$ & $(12.7)$ & $(13.5)$ & $(13.4)$ & $(14.8)$ & $(11.0)$ & $(18.2)$ \\
OT & Mean & 88.0 & 90.8 & 88.0 & 91.4 & 91.6 & 82.2 & 90.0 & 51.5 \\
& $(\mathrm{SD})$ & $(15.9)$ & $(6.9)$ & $(11.1)$ & $(17.7)$ & $(8.8)$ & $(11.1)$ & $(9.1)$ & $(15.9)$ \\
Male & Mean & 99.6 & 99.6 & 99.6 & 103.6 & 100 & 88.0 & 91.6 & 49.17 \\
& $(\mathrm{SD})$ & $(19.0)$ & $(10.4)$ & $(14.7)$ & $(20.6)$ & $(13.3)$ & $(11.1)$ & $(12.6)$ & $(19.6)$ \\
Female & Mean & 84.29 & 90.2 & 85.8 & 86.6 & 90.7 & 80.7 & 90.2 & 61.43 \\
& $(\mathrm{SD})$ & $(10.4)$ & $(7.7)$ & $(7.7)$ & $(9.3)$ & $(9.4)$ & $(13.2)$ & $(9.0)$ & $(16.4)$ \\
$<\mathbf{5}$ years of age at & Mean & 104.3 & 105.6 & 106.0 & 105.3 & 104.3 & 99.0 & 98.3 & 68.3 \\
diagnosis IT & $(\mathrm{SD})$ & $(9.8)$ & $(8.6)$ & $(7.5)$ & $(10.7)$ & $(19.6)$ & $(0.0)$ & $(14.7)$ & $(25.6)$ \\
$\mathbf{2 5}$ years of age at & Mean & 83.5 & 90.8 & 86.0 & 86.4 & 91.7 & 77.1 & 88.2 & 62.1 \\
diagnosis IT & $(\mathrm{SD})$ & $(11.7)$ & $(9.6)$ & $(9.2)$ & $(10.5)$ & $(9.3)$ & $(12.8)$ & $(8.6)$ & $(18.2)$ \\
$\begin{array}{l}<5 \text { years of age at } \\
\text { diagnosis OT }\end{array}$ & Mean & 83.0 & 87.0 & 83.3 & 84.8 & 86.8 & 81.0 & 91.1 & 50.8 \\
$\begin{array}{l}\mathbf{5} \text { years of age at } \\
\text { diagnosis OT }\end{array}$ & $(\mathrm{SD})$ & $(11.9)$ & $(5.9)$ & $(8.5)$ & $(10.3)$ & $(6.3)$ & $(13.1)$ & $(10.1)$ & $(20.1)$ \\
\hline
\end{tabular}

Expected scores for IQs and WISC-III: 89-109 points. IT, in treatment; OT, off treatment; VIQ, verbal intelligence quotient; PIQ, performance intelligence quotient; FSIQ, full-scale intelligence quotient; VCI, verbal comprehension index; POI, perceptual organization index; FDI, freedom from distractibility index (FDI); PCI, processing speed index; RPCM, Raven's Colored Progressive Matrices. 
Table 4. Mean and standard deviation of performance scores in the groups and subgroups on the WCST

\begin{tabular}{|c|c|c|c|c|c|c|c|c|c|}
\hline Group & & $\mathbf{P E}$ & PPR & PPE & PNPE & PCLR & $\mathrm{CC}$ & FMS & $\mathbf{L L}$ \\
\hline IT & $\begin{array}{l}\text { Mean } \\
\text { (SD) }\end{array}$ & $\begin{array}{l}32.6 \\
(28.8)\end{array}$ & $\begin{array}{l}4.3 \\
(6.4)\end{array}$ & $\begin{array}{l}2.7 \\
(3.5)\end{array}$ & $\begin{array}{l}61.5 \\
(30.3)\end{array}$ & $\begin{array}{l}40.2 \\
(29.5)\end{array}$ & $\begin{array}{l}4.4 \\
(0.8)\end{array}$ & $\begin{array}{l}4.8 \\
(0.6)\end{array}$ & $\begin{array}{l}1.5 \\
(2.0)\end{array}$ \\
\hline OT & $\begin{array}{l}\text { Mean } \\
\text { (SD) }\end{array}$ & $\begin{array}{l}59.5 \\
(35.1)\end{array}$ & $\begin{array}{l}10.9 \\
(13.0)\end{array}$ & $\begin{array}{l}11.5 \\
(15.3)\end{array}$ & $\begin{array}{l}55.2 \\
(30.1)\end{array}$ & $\begin{array}{l}58.6 \\
(34.4)\end{array}$ & $\begin{array}{l}4.3 \\
(1.4)\end{array}$ & $\begin{array}{l}4.6 \\
(1.2)\end{array}$ & $\begin{array}{l}3.0 \\
(2.2)\end{array}$ \\
\hline Male & $\begin{array}{l}\text { Mean } \\
\text { (SD) }\end{array}$ & $\begin{array}{l}49.3 \\
(39.6)\end{array}$ & $\begin{array}{l}7.3 \\
(8.8)\end{array}$ & $\begin{array}{l}10.8 \\
(18.0)\end{array}$ & $\begin{array}{l}56.3 \\
(34.5)\end{array}$ & $\begin{array}{l}48.1 \\
(38.6)\end{array}$ & $\begin{array}{l}4.1 \\
(1.6)\end{array}$ & $\begin{array}{l}5.0 \\
(0.0)\end{array}$ & $\begin{array}{l}1.8 \\
(2.4)\end{array}$ \\
\hline Female & $\begin{array}{l}\text { Mean } \\
\text { (SD) }\end{array}$ & $\begin{array}{l}44.6 \\
(33.1)\end{array}$ & $\begin{array}{l}7.7 \\
(11.4)\end{array}$ & $\begin{array}{l}5.5 \\
(8.2)\end{array}$ & $\begin{array}{l}59.2 \\
(28.5)\end{array}$ & $\begin{array}{l}49.9 \\
(31.3)\end{array}$ & $\begin{array}{l}4.4 \\
(1.0)\end{array}$ & $\begin{array}{l}4.5 \\
(1.1)\end{array}$ & $\begin{array}{l}2.4 \\
(2.1)\end{array}$ \\
\hline $\begin{array}{l}<5 \text { years of age at } \\
\text { diagnosis IT }\end{array}$ & $\begin{array}{l}\text { Mean } \\
\text { (SD) }\end{array}$ & $\begin{array}{l}35.0 \\
(32.7)\end{array}$ & $\begin{array}{l}6.0 \\
(8.7)\end{array}$ & $\begin{array}{l}4.0 \\
(4.5)\end{array}$ & $\begin{array}{l}58.3 \\
(41.3)\end{array}$ & $\begin{array}{l}56.6 \\
(28.3)\end{array}$ & $\begin{array}{l}4.3 \\
(1.1)\end{array}$ & $\begin{array}{l}5.0 \\
(0.0)\end{array}$ & $\begin{array}{l}0.33 \\
(0.5)\end{array}$ \\
\hline $\begin{array}{l}\geq 5 \text { years of age at } \\
\text { diagnosis IT }\end{array}$ & $\begin{array}{l}\text { Mean } \\
\text { (SD) }\end{array}$ & $\begin{array}{l}31.5 \\
(29.7)\end{array}$ & $\begin{array}{l}3.5 \\
(5.8)\end{array}$ & $\begin{array}{l}2.1 \\
(3.3)\end{array}$ & $\begin{array}{l}62.8 \\
(28.2)\end{array}$ & $\begin{array}{l}32.7 \\
(28.7)\end{array}$ & $\begin{array}{l}4.4 \\
(0.7)\end{array}$ & $\begin{array}{l}4.71 \\
(0.7)\end{array}$ & $\begin{array}{l}2.0 \\
(2.0)\end{array}$ \\
\hline $\begin{array}{l}<5 \text { years of age at } \\
\text { diagnosis OT }\end{array}$ & $\begin{array}{l}\text { Mean } \\
\text { (SD) }\end{array}$ & $\begin{array}{l}43.1 \\
(36.1)\end{array}$ & $\begin{array}{l}10.6 \\
(15.7)\end{array}$ & $\begin{array}{l}7.0 \\
(10.5)\end{array}$ & $\begin{array}{l}48.0 \\
(33.5)\end{array}$ & $\begin{array}{l}43.6 \\
(36.3)\end{array}$ & $\begin{array}{l}3.8 \\
(1.8)\end{array}$ & $\begin{array}{l}4.3 \\
(1.6)\end{array}$ & $\begin{array}{l}1.6 \\
(1.9)\end{array}$ \\
\hline $\begin{array}{l}\geq 5 \text { years of age at } \\
\text { diagnosis OT }\end{array}$ & $\begin{array}{l}\text { Mean } \\
\text { (SD) }\end{array}$ & $\begin{array}{l}84.0 \\
(14.0)\end{array}$ & $\begin{array}{l}11.2 \\
(9.6)\end{array}$ & $\begin{array}{l}18.2 \\
(20.5)\end{array}$ & $\begin{array}{l}66.0 \\
(24.2)\end{array}$ & $\begin{array}{l}81.0 \\
(15.4)\end{array}$ & $\begin{array}{l}5.0 \\
(0.0)\end{array}$ & $\begin{array}{l}5.0 \\
(0.0)\end{array}$ & $\begin{array}{l}5.0 \\
(0.0)\end{array}$ \\
\hline
\end{tabular}

IT, in treatment; OT, off treatment; PE, percent errors; PPR, percent perseverative responses; PPE, percentage perseverative errors; PNPE, percent nonperseverative errors; PCLR, percent conceptual-level responses; CC, categories completed; FMS, failure to maintain set; LL, learning to learn.

Statistical comparisons of groups and subgroups revealed a significant difference in performance only on sum of words from A1 through A5 (SA) in the treatment group when considering the age at diagnosis, with better performance in the group diagnosed before 5 years of age $(p=.049)$.

\section{Discussion}

Overall, the present results suggest that children diagnosed with ALL and subjected to intrathecal chemotherapy display mild cognitive function deficits that can limit their daily activities, such as performance at school, insertion into the job market, autonomy and quality of life (Langer et al., 2002; Carey et al., 2007; Buizer, Soneville, \& Veerman, 2009).

With regard to global intellectual performance, we found that global IQ measured by the WISC-III was $<90$ in $50 \%$ of the subjects, which is less than the threshold for the expected average. This low score was mainly observed in the risk group associated with the cognitive impacts of prophylactic ALL treatment (i.e., children who were off treatment, female and $<5$ years of age at diagnosis).

Table 5. Mean and standard deviation of performance scores in the groups and subgroups on the Rey Auditory Verbal Learning Test (RAVLT) and Story Recall (SR)

\begin{tabular}{|c|c|c|c|c|c|c|c|c|c|}
\hline Group & & A1 & SA & B1 & A6 & A7 & REC & ISR & DSR \\
\hline IT & $\begin{array}{l}\text { Mean } \\
\text { (SD) }\end{array}$ & $\begin{array}{l}0.00 \\
(0.88)\end{array}$ & $\begin{array}{l}-0.84 \\
(0.89)\end{array}$ & $\begin{array}{l}-1.15 \\
(2.36)\end{array}$ & $\begin{array}{l}-1.06 \\
(2.08)\end{array}$ & $\begin{array}{l}-1.02 \\
(1.73)\end{array}$ & $\begin{array}{l}-0.13 \\
(1.68)\end{array}$ & $\begin{array}{l}-0.20 \\
(1.14)\end{array}$ & $\begin{array}{l}0.83 \\
(2.23)\end{array}$ \\
\hline OT & $\begin{array}{l}\text { Mean } \\
\text { (SD) }\end{array}$ & $\begin{array}{l}0.07 \\
(1.37)\end{array}$ & $\begin{array}{l}-0.12 \\
(1.18)\end{array}$ & $\begin{array}{l}-1.23 \\
(2.03)\end{array}$ & $\begin{array}{l}-0.12 \\
(1.82)\end{array}$ & $\begin{array}{l}-0.92 \\
(1.24)\end{array}$ & $\begin{array}{l}0.10 \\
(0.74)\end{array}$ & $\begin{array}{l}-0.50 \\
(1.47)\end{array}$ & $\begin{array}{l}-0.42 \\
(1.19)\end{array}$ \\
\hline Male & $\begin{array}{l}\text { Mean } \\
\text { (SD) }\end{array}$ & $\begin{array}{l}-0.39 \\
(0.90)\end{array}$ & $\begin{array}{l}-0.41 \\
(0.85)\end{array}$ & $\begin{array}{l}-1.61 \\
(1.62)\end{array}$ & $\begin{array}{l}-0.32 \\
(1.43)\end{array}$ & $\begin{array}{l}-1.06 \\
(1.92)\end{array}$ & $\begin{array}{l}0.04 \\
(0.41)\end{array}$ & $\begin{array}{l}-0.10 \\
(1.28)\end{array}$ & $\begin{array}{l}1.11 \\
(3.32)\end{array}$ \\
\hline Female & $\begin{array}{l}\text { Mean } \\
\text { (SD) }\end{array}$ & $\begin{array}{l}0.21 \\
(1.19)\end{array}$ & $\begin{array}{l}-0.51 \\
(1.20)\end{array}$ & $\begin{array}{l}-1.04 \\
(2.34)\end{array}$ & $\begin{array}{l}-0.72 \\
(2.16)\end{array}$ & $\begin{array}{l}-0.95 \\
(1.37)\end{array}$ & $\begin{array}{l}0.06 \\
(1.53)\end{array}$ & $\begin{array}{l}-0.40 \\
(1.30)\end{array}$ & $\begin{array}{l}0.03 \\
(1.39)\end{array}$ \\
\hline $\begin{array}{l}<5 \text { years of age at } \\
\text { diagnosis IT }\end{array}$ & $\begin{array}{l}\text { Mean } \\
\text { (SD) }\end{array}$ & $\begin{array}{l}-0.45 \\
(0.39)\end{array}$ & $\begin{array}{l}-0.14 \\
(0.45)\end{array}$ & $\begin{array}{l}-0.07 \\
(1.66)\end{array}$ & $\begin{array}{l}-0.37 \\
(0.51)\end{array}$ & $\begin{array}{l}-0.17 \\
(0.59)\end{array}$ & $\begin{array}{l}0.01 \\
(0.25)\end{array}$ & $\begin{array}{l}-0.18 \\
(1.57)\end{array}$ & $\begin{array}{l}1.65 \\
(3.88)\end{array}$ \\
\hline $\begin{array}{l}\geq 5 \text { years of age at } \\
\text { diagnosis IT }\end{array}$ & $\begin{array}{l}\text { Mean } \\
(\mathrm{SD})\end{array}$ & $\begin{array}{l}0.19 \\
(0.98)\end{array}$ & $\begin{array}{l}-1.14 \\
(0.88)\end{array}$ & $\begin{array}{l}-1.62 \\
(2.56)\end{array}$ & $\begin{array}{l}-1.35 \\
(2.47)\end{array}$ & $\begin{array}{l}-1.39 \\
(1.96)\end{array}$ & $\begin{array}{l}-0.20 \\
(2.12)\end{array}$ & $\begin{array}{l}-0.20 \\
(1.06)\end{array}$ & $\begin{array}{l}0.47 \\
(1.41)\end{array}$ \\
\hline $\begin{array}{l}<5 \text { years of age at } \\
\text { diagnosis OT }\end{array}$ & $\begin{array}{l}\text { Mean } \\
\text { (SD) }\end{array}$ & $\begin{array}{l}0.45 \\
(1.68)\end{array}$ & $\begin{array}{l}-0.14 \\
(1.40)\end{array}$ & $\begin{array}{l}-1.91 \\
(2.19)\end{array}$ & $\begin{array}{l}-0.35 \\
(2.13)\end{array}$ & $\begin{array}{l}-1.27 \\
(1.11)\end{array}$ & $\begin{array}{l}0.43 \\
1.68)\end{array}$ & $\begin{array}{l}-1.07 \\
(1.62)\end{array}$ & $\begin{array}{l}-0.85 \\
(1.31)\end{array}$ \\
\hline $\begin{array}{l}\geq 5 \text { years of age at } \\
\text { diagnosis OT }\end{array}$ & $\begin{array}{l}\text { Mean } \\
\text { (SD) }\end{array}$ & $\begin{array}{l}-0.50 \\
(0.45)\end{array}$ & $\begin{array}{l}-0.80 \\
(0.96)\end{array}$ & $\begin{array}{l}0.14 \\
(0.58)\end{array}$ & $\begin{array}{l}0.34 \\
(1.17)\end{array}$ & $\begin{array}{l}-0.23 \\
(1.41)\end{array}$ & $\begin{array}{l}-0.35 \\
(0.88)\end{array}$ & $\begin{array}{l}0.44 \\
(0.43)\end{array}$ & $\begin{array}{l}0.30 \\
(0.50)\end{array}$ \\
\hline
\end{tabular}

IT, in treatment; OT, off treatment; A1, attempt 1 in list A; SA, sum of words from A1 through A5; B1, list of interference; A6, attempt 6 in list A; A7, attempt 7 in list A; REC, recognition; ISR, immediate story recall; DSR, delayed story recall. 
Table 6. Differences between gender groups (male vs. female) and age at the time of diagnosis in terms of Intellectual Performance, Executive Functions and Memory*

\begin{tabular}{|c|c|c|c|c|c|c|c|}
\hline & $\begin{array}{l}\text { Groups/ } \\
\text { Subgroups }\end{array}$ & $\begin{array}{l}\text { Male } \\
\text { vs. } \\
\text { Female }\end{array}$ & & $\begin{array}{l}<5 \text { years } v s . \\
\text { diagnosis } \\
\text { (IT) }\end{array}$ & years old at & $\begin{array}{l}<5 \text { years } v s . \\
\text { diagnosis } \\
(\text { OT) }\end{array}$ & years old at \\
\hline & Measures & $\begin{array}{l}\text { Mann- } \\
\text { Whitney U }\end{array}$ & $t$ test & $\begin{array}{l}\text { Mann- } \\
\text { Whitney U }\end{array}$ & $t$ test & $\begin{array}{l}\text { Mann- } \\
\text { Whitney U }\end{array}$ & $t$ test \\
\hline \multirow{8}{*}{$\begin{array}{l}\text { Intellectual } \\
\text { performance }\end{array}$} & VIQ & & 0.031 & & 0.029 & & 0.247 \\
\hline & PIQ & & 0.037 & & 0.050 & & 0.015 \\
\hline & FSIQ & & 0.012 & & 0.011 & & 0.108 \\
\hline & $\mathrm{VCI}$ & 0.062 & & & 0.033 & & 0.162 \\
\hline & POI & & 0.093 & & 0.188 & & 0.025 \\
\hline & FID & & 0.259 & 0.015 & & & 0.677 \\
\hline & PSI & & 0.773 & & 0.203 & & 0.640 \\
\hline & RPCM & & 0.166 & & 0.651 & & 0.883 \\
\hline \multirow[t]{8}{*}{ Executive function } & $\mathrm{PE}$ & & 0.787 & & 0.875 & 0.131 & \\
\hline & PPR & & 0.937 & & 0.614 & & 0.949 \\
\hline & PPE & & 0.367 & & 0.486 & & 0.282 \\
\hline & PNPE & & 0.848 & & 0.843 & & 0.354 \\
\hline & PCLR & & 0.915 & & 0.243 & 0.109 & \\
\hline & $\mathrm{CC}$ & & 0.662 & & 0.881 & 0.224 & \\
\hline & FMS & & 0.189 & & 0.545 & & 0.363 \\
\hline & LL & & 0.597 & 0.327 & & 0.022 & \\
\hline \multirow[t]{8}{*}{ Memory } & A1 & & 0.242 & & 0.179 & 0.748 & \\
\hline & AS & & 0.835 & & 0.049 & & 0.947 \\
\hline & B1 & & 0.565 & & 0.300 & & 0.075 \\
\hline & A6 & & 0.654 & & 0.352 & & 0.556 \\
\hline & A7 & & 0.891 & & 0.174 & & 0.266 \\
\hline & REC & & 0.845 & & 0.816 & & 0.190 \\
\hline & ISR & & 0.693 & & 0.982 & 0.297 & \\
\hline & DSR & 0.791 & & 0.732 & & 0.297 & \\
\hline
\end{tabular}

Note: Statistical value of $p$ for null hypothesis $\leq 0.05$ (two-tailed) indicated in bold characters. VIQ, verbal intelligence quotient; PIQ, performance intelligence quotient; FSIQ, full scale intelligence quotient; VCI, verbal comprehension index; POI, perceptual organization index; FDI, freedom from distractibility index (FDI); PCI, the processing speed index; RPCM, Raven's Colored Progressive Matrices; IT, in treatment; OT, off treatment; PE, percent errors; PPR, percent perseverative responses; PPE, percentage perseverative errors; PNPE, percent nonperseverative errors; PCLR, percent conceptual-level responses; CC, categories completed; FMS, failure to maintain set; LL, learning to learn; A1, attempt 1 in list A; SA, sum of words from A1 through A5; B1, list of interference; A6, attempt 6 in list A; A7, attempt 7 in list A; REC, recognition; ISR, immediate story recall; DSR, delayed story recall.

The present results are consistent with previous studies that suggested greater vulnerability to the toxicity of prophylactic chemotherapy in females (Mulhern \& Palmer, 2003; Von der Weid et al., 2003; Moore, 2005; Spiegler et al., 2006; Peterson et al., 2008). Despite the lack of consensus, some studies suggested that this outcome may be attributable to an interaction between hormonal factors and the drugs used or even the differences in brain maturation between genders (Von der Weid et al., 2003).

Concerning the occurrence of sequelae associated with the age at the time of diagnosis, the present results are consistent with the literature, with lower scores in the subgroup of children who were diagnosed before 5 years of age and off treatment (Buizer et al., 2005). Notably, in the functions frequently preserved in the other subgroups, such as performance IQ and the POI, the subgroup diagnosed before 5 years of age and off treatment displayed significantly lower scores. These findings suggest higher vulnerability of the immature brain to the neurotoxic insults of chemotherapy (Buizer et al., 2005).

Interestingly, the FDI was less than the expected FDI for virtually all groups and subgroups with the exception of children diagnosed before the age of 5 years and in treatment. Further qualitative analysis revealed poor performance in the various groups and subgroups in the FDI, especially on the Arithmetic subtests. Lofstad et al. (2009) found similar results and reported a reduction of the FDI and verbal function as a whole. Scores were slightly less than the average for females. 
With regard to attention, we did not find significant differences between the groups or subgroups and we did not identify the presence of attention deficits in any of the subgroups. However, we did observe lower scores, mainly in the number of correct responses on part 3 of the test that investigated selectivity/alternation, compared with the scores of healthy children in the same age group. These findings are consistent with the observations by Buizer et al. (2005) who reported that children with ALL and who received standard treatment had similar performance as healthy children in attention and information processing, with the exception of attention flexibility.

Mennes et al. (2005) reported that their results, which were similar to the present results, disagreed with some findings obtained in children who were cured of ALL and experienced attention capacity problems. These authors suggested that these findings indicate that complaints derived mainly from mild deficits in the speed of information processing, in addition to the complexity of the task, were deficits related to the ability of attention flexibility, and difficulties maintaining performance in a prolonged task.

According to Mulhern \& Palmer (2003) and Buizer et al. (2005), several of the core deficits exhibited by ALL survivors are defined by the term "executive function," characterized by the capacity to allocate attention resources and organize behavior and thinking, which rely on the integrity of the prefrontal cortex. We found that the lowest scores were in the group of children in treatment compared with the children off treatment.

With regard to the children's age at the time of diagnosis, data were similar to those obtained on the WISC-III. The subgroup of children in treatment who were diagnosed before 5 years of age had a better performance average than the group of children who were diagnosed at 5 years of age or older. The subgroup of children off treatment who were diagnosed before 5 years of age had poorer performance than the group of children who were diagnosed at 5 years of age or older. Cole \& Kamen (2006) suggested that detecting adverse neurocognitive effects during the initial phases of treatment is possible, perhaps because of the acute and subacute toxicity of anti-leukemia therapy. However, these effects have been considered transient and tend to disappear in most cases without intervention. These authors suggested that the deficits may persist for many years or even be permanent if they are identified late (Cole \& Kamen, 2006).

The performance of children with ALL on the items that evaluate perseverative behavior, including perseverative responses and perseveration errors, was the most affected and can be classified as moderately compromised, mildly to moderately compromised and mildly compromised. Data revealed specific executive function in these children, notably in terms of the inhibition of alternative or inadequate responses, updating and monitoring information and changes in mental patterns (Mello, 2008).
Studies have attempted to understand how chemotherapy impacts the function of frontal brain areas and have also investigated the relationships with the neurodevelopment processes of brain areas related to executive function, marked by a more prolonged developmental course during childhood and adolescence, especially myelination in prefrontal and frontal structures. The majority of these studies determined that the distribution and proliferation of white matter were the main factors associated with such deficits (Moleski, 2000; Carey et al., 2007; Campbell et al., 2009). One hypothesis is that developing areas are more susceptible to injuries or lesions than mature areas (Buizer et al., 2005).

With regard to episodic memory, the groups' performance was similar to expected performance, with the exception of the group of children off treatment who were diagnosed before 5 years of age, in which the global average (both immediate and delayed) was approximately one standard deviation less than the reference group. Interestingly, better performance was observed in all groups in the delayed memory task compared with the immediate memory task.

With regard to semantic memory, the scores on the RAVLT were comparable to the scores on the Digits subtest of the WISC-III in which the different groups and subgroups had performance scores that were within or very close to the expected range. Similar scores were found in the recognition phase, suggesting effective memory consolidation (Mello, 2008).

Working memory was evaluated by the Digits and Arithmetic subtests of the WISC-III that, when combined, constitute the FDI. A reduction of scores was found on this index, mainly attributable to performance on the Arithmetic subtest, which involves working memory in addition to other cognitive resources. A clinical analysis of the results of this subtest revealed two important aspects: $(i)$ repeated requests that the examiner repeat the problem and (ii) difficulty performing mental operations without the aid of concrete objects. The lack of instruments designed to scientifically evaluate other aspects such as mathematical knowledge makes drawing definitive conclusions difficult.

The present study also revealed important differences between the performance of boys and girls, with girls displaying poorer performance than expected in most of the measures, especially on verbal tasks. The processing characteristics and developmental immaturity of the CNS may have contributed to these findings, especially concerning frontal regions. Additionally, socioemotional variables associated with the disease process and treatment may also be involved in the difficulty experienced by the children who were still in treatment and developing.

\section{Concluding remarks}

Research on the cognitive effects of illness and treatment in children with cancer in the pediatric 
oncology field in the past decades has increased patient survival. However, controversial results and a lack of research on this topic still exist in Brazil. Variations in the methodologies used to elaborate and operationalize the results, such as sample size, inclusion of control groups, specific evaluation tools, characteristics of the disease itself and current therapeutic protocols have hindered the generalization and consolidation of the results.

Further studies on the neuropsychological impacts of ALL pathology and treatment are necessary. Such knowledge is needed to develop rational and satisfactory strategies to intervene and minimize possible deficits, thus contributing to a better quality of life for these children.

A limitation of the present study was the low number of subjects in some of the specific subgroups such as the group of male. Further studies are necessary to investigate other specific aspects of cognition. Such studies will contribute to the development of therapeutic strategies that minimize drug toxicity but retain treatment efficacy.

\section{References}

Buizer, A. I., Soneville, L. M. J., \& Veerman, A. J. P. (2009). Effects of chemotherapy on neurocognitive function in children with acute lymphoblastic leukemia: A critical review of the literature. Pediatric Blood Cancer, 52, 447-454.

Buizer, A. I., Soneville, L. M. J., Van Den Heuvel-Eibrink, M. M., Njiokiktjien, C., \& Veerman, A. J. P. (2005). Visuomotor control in survivors of childhood acute lymphoblastic leukemia treated with chemotherapy only. Journal of the International Neuropsychological Society 11, 554-565.

Butler, R. W., \& Haser, J. K. (2006). Neurocognitive effects of treatment for childhood cancer. Mental Retardation and Developmental Disabilities Research Review, 12(3), 184-191.

Campbell, L. K., Scaduto, M., Sharp, W., Dufton, L., Van Slyke, D., Whitlock, J. A., \& Compas, B. (2007). A meta-analysis of the neurocognitive sequelae of treatment for childhood acute lymphocytic leukemia. Pediatric Blood \&Cancer, 49(1), 65-73.

Campbell, L. K., Scaduto, M., Van Slyke, D., Niarhos, F., \& Whitlock, J. A. (2009). Executive function, coping, and behavior in survivors of childhood acute lymphocytic leukemia. Journal of Pediatric Psychology, 34(3), 317-327.

Carey, M. E., Hockenberry, M. J., Morre, I. M., Hutter, J. J., Krull, K. R., Pasvogel, A., \& Kaemingk, K. L. (2007). Brief report: Effect of intravenous methotrexate dose and infusion rate on neuropsychological function one year after diagnosis of acute lymphoblastic leukemia. Journal of Pediatric Psychology, 32(2), 189-193.

Cazé, M. O., Bueno, D., \& Santos, M. E. F. (2010). Estudo referencial de um protocolo quimioterápico para leucemia linfocítica aguda infantil. Revista do Hospital de Clínicas de Porto Alegre, 30(1), 5-12.

Cole, P. D., \& Kamen, B. A. (2006). Delayed neurotoxicity associated with therapy for children with acute lymphoblastic leukemia. Mental Retardation and Developmental Disabilities Research Review, 12(3), 174-183.

Filho, V. D., Maluf, P. T. Jr., Cristofani, L. M., Almeida, M. T. A. \& Teixeira, R. A. P. (2012). Doenças Neoplásicas da Criança e do Adolescente - Coleção Pediatria do Instituto da Criança HCFMUSP, v. 22. Barueri: Manole.

Gomes, E. (2011). Investigação do funcionamento cognitivo de pacientes pediátricos diagnosticados com leucemia linfóide aguda - LLA. Dissertação de Mestrado, Universidade Federal do Rio Grande do Norte, Natal, RN, Brasil.

Instituto Nacional do Câncer (2012). Coordenação de Prevenção e Vigilância do Câncer. Câncer no Brasil: dados dos registros de base populacional, vol. 4. Rio de Janeiro: INCA.
Langer, T., Martus, P., Ottensmeier, H., Hertzberg, H., Beck, J. D., \& Meier, W. (2002). CNS late-effects after ALL therapy in childhood. III: neuropsychological performance in long-term survivors of childhood ALL: Impairments of concentration, attention, and memory. Medical Pediatric Oncology, 38(5), 320-328.

Leite, E. P., Muniz, M. T. C., Azevedo, A. C. A. C., Souto, F. R., Maia, A. C. L., Gondim, C. M. F., Gondim, C. M. F., \& Melo, R. A. M. (2007). Fatores prognósticos em crianças e adolescentes com leucemia linfóide aguda. Revista Brasileira de Saúde Materno Infantil, 7(4), 413-421.

Lezak, M. D. (2004). Neuropsychological assessment. New York: Oxford University Press.

Lofstad, G. E., Reinfjell, T., Hestad, K., \& Diseth, T. H. (2009). Cognitive outcome in children and adolescents treated for acute lymphoblastic leukaemia with chemotherapy only. Acta Pcediatrica, 98, 180-186.

Mello, C. B. (2008). Memória. In M. Muszkat, \& C. B. de Mello, Neuropsicologia do desenvolvimento e suas interfaces (pp. 158172). São Paulo: All Print Editora.

Mennes, M., Stiers, P., Vandenbussche, E., Vercruysse, G., Uyttebroeck, A., Meyer, G., \& Gool, S. W. V. (2005). Pediatric Blood \& Cancer, 44, 479-486.

Moleski, M. (2000). Neuropsychological, neuroanatomical and neurophysiological consequences of CNS chemotherapy for acute lymphoblastic leukemia. Archives of Clinical Neuropsychology, 15(7),603-630.

Montiel, J., \& Capovilla, A. (2007). Avaliação da atenção: Teste de Atenção por Cancelamento. In A. Capovilla, \& F. C. Capovilla (Eds.), Teoria e pesquisa em avaliação neuropsicológica (pp. 119124). São Paulo: Memnon.

Moore, D. (2005). Neurocognitive outcomes in survivors of childhood cancer. Journal of Pediatric Psychology, 30(1), 51-63.

Mulhern, R., \& Palmer, S. (2003). Neurocognitive late effects in pediatric cancer. Current Problems in Cancer, 27(4), 177-197.

Neglia, J., O'Leary, M., \& Bhatia, S. (2011). Late sequelae in children with acute lymphoblastic leukemia: Impact on longterm survival and quality of life. In G. H. Reaman, \& F. O. Smith, Childhood leukemia: A practical handbook (pp. 245-263), Berlin: Springer.

Pedrosa, F., \& Lins, M. (2002). Leucemia linfóide aguda: Uma doença curável. Revista Brasileira de Saúde Materno Infantil, 2(1), 63-68.

Peterson, C., Johnson, C. E., Ramirez, L. Y., Huestis, S., Pai, A. L. H., Demaree, H. A., \& Drotar, D. (2008). A meta-analysis of the neuropsychological sequelae of chemotherapy-only treatment for pediatric acute lymphoblastic leukemia. Pediatric Blood \& Cancer, 51(1), 99-104.

Spiegler, B. J., Kennedy, K., Maze, R., Greenberg, M. L., Weitzman, S., Hitzler, J. K., \& Nathan, P. C. (2006). Comparison of longterm neurocognitive outcomes in young children with acute lymphoblastic leukemia treated with cranial radiation or high-dose or very high-dose intravenous methotrexate. Journal of Clinical Oncology, 24(24), 3858-3864.

Temning, P., \& Jenney, M. E. M. (2010). The neurodevelopmental sequelae of childhood leukaemia and its treatment. Archives of Disease in Childhood, 95, 936-940.

Von der Weid, N., Mosimann, I., Hirt, A., Wacker, P., Nenadov Beck, M., Imbach, P., ... Wagner, H. P. (2003). Intellectual outcome in children and adolescents with acute lymphoblastic leukaemia treated with chemotherapy alone: Age- and sex-related differences. European Journal of Cancer, 39, 359-365.

Waber, D. P., Turek, J., Catania, L., Stevenson, K., Robaey, P., Romero, I., ... Silverman, L. B. (2007). Neuropsychological outcomes from a randomized trial of triple intrathecal chemotherapy compared with 18 Gy cranial radiation as CNS treatment in acute lymphoblastic leukemia: Findings from Dana-Farber Cancer Institute ALL Consortium Protocol 95-01. Journal of Clinical Oncology, 26(4), 4914-4921.

Waber, D. P., Queally, J. T., Catania, L., Robaey, P., Romero, I., Adams, H., ... Silverman, L. B. (2012). Neuropsychological outcomes of standard risk and high risk patients treated for acute lymphoblastic leukemia on Dana-Farber ALL consortium protocol $95-01$ at 5 years post-diagnosis. Pediatric Blood \& Cancer, 58(5), 758-765. 